\title{
Correlations Regarding Microbial Contamination Level and Oxidative Spoilage in Frozen Beef, Pork, Poultry and Fish Meat
}

\author{
Silviu VIDA, Sorin Daniel DAN*, Adela PINTEA, Marian MIHAIU, Alexandra TABARAN \\ ${ }^{1}$ Department of Animal Production and Food Safety, University of Agricultural Sciences and Veterinary \\ Medicine, Faculty of Veterinary Medicine, 3-5 Mănăștur Street, 400372, \\ ClujNapoca, Romania \\ *Corresponding author: sorindan@usamvcluj.ro
}

Bulletin UASVM Veterinary Medicine 72(2) / 2015,

Print ISSN 1843-5270; Electronic ISSN 1843-5378

DOI:10.15835/buasvmcn-vm: 11593

\begin{abstract}
Studies concerning food safety and meat quality have increased considerably over the past few years. Lipids oxidation represents one major cause of sensorial changes and quality loss of meat. Also, is responsible for reducing the shelf life, being influenced by the temperature and time of meat storage. The aim of this study was represented by the assessment of oxidation spoilage processes through determination of thiobarbituric acid (TBARS) correlated with the load and configuration of psychotropic microflora of beef, pork, poultry and fish meat. The research material analysed was represented by 27 samples collected from 3 different batches of beef, pork, and poultry and fish meat, purchased from the retail network of a hypermarket from Cluj County. The samples have been carried in isothermal bags at the Food inspection and control laboratory from FVM Cluj-Napoca, and they have been kept at freezing temperatures $\left(-20^{\circ} \mathrm{C}\right)$. In order to assess in dynamic the oxidative spoilage processes, there have been carried out 3 analyses during the experiment: July 2014, December 2014 and May 2015. From the research of the give results regarding the oxidative processes it has been determined in the meat samples that the thiobarbituric acid (TBARS) represented in dynamics an ascendant evolution, the highest values being in poultry in the first day of the experiment $14.4 \pm 0.4$ and $19.74 \pm 1.16 \mathrm{nmol} / 100 \mathrm{~g}$ malondialdehyde (MDA). Rephrase, difficult to follow The microbial load of meat samples presented a descendent evolution during the storage at $-20^{\circ} \mathrm{C}$, from $4.9 \pm 0.31 \log \mathrm{cfu} / \mathrm{g}$ at the beginning of the experiment to $4.1 \pm 0.26 \log \mathrm{cfu} / \mathrm{g}$ in the last day.
\end{abstract}

Keywords: microbioal load, oxidative spoilage, psychrotrophic bacteria

\section{INTRODUCTION}

Studies concerning food safety and quality of meat have increased considerably over the past few years. Lipids oxidation represents one major cause of sensorial changes and quality loss of meat and generates compounds which can be harmful for human health (Addis, 1986; Min and Ahn, 2005). Also, is responsible for reducing the shelf life, being influenced by the temperature and time of meat storage (Okolie and Osarhiene, 2013). The lipid oxidation rate in meat depends on the balance between the endogenous and exogenous factors which are found in meat (Kanner, 1994).
The endogenous factors include the total lipid content, the composition of fatty acids in fat, the types and iron quantities present, natural antioxidants (camosine, anserine andtocopherol), as well as antioxidant enzymes (catalase, superoxide dismutase, etc.) (Chan and Decker 1994; Min and Ahn, 2005).The exogenous factors include the presence of oxygen, salts adding, as well as the noncompliance with the temperature conditions during the meat manipulation and distribution. The susceptibility of lipid oxidation in meat varies according to the species from which the meat comes from, as well as the 
anatomical region. Poultry meat is very sensitive to the development of oxidative processes due to its high content of polyunsaturated fatty acids. Numerous studies have been made regarding the oxidative processes in poultry meat which show an increase of the reactive substances quantities like the thyobarbituric acid (TBARS) during the storage at cold (Pikul et al., 1989). Food storage through refrigeration is universally accepted as an efficient method for their efficient preservation. A limitative factor of this type of preservation is represented by the presence of psychotropic bacteria which have a spoilage effect on meat even in low temperatures (Nashif et al., 1953; Afford et al., 1960; Khan, 1967). The oxidative processes are not blocked following the refrigeration process; they are just slowed down, being influenced by the temperature in which meat is kept. The closer the temperature to $0^{\circ} \mathrm{C}$, the slower the oxidation process. The lipolysis process is influenced by the presence of lypolitic enzymes, characteristic for the muscle tissue, as well as the exogenous ones, respectively bacterial (Afford et al., 1961).

\section{MATERIALS AND METHODS}

The research material submitted was represented by 27 samples collected from 3 different batches of beef, pork, poultry and fish meat, purchased from the retail network of a hypermarket from Cluj County. The samples have been carried in isothermal bags at the Food inspection and control laboratory from FVM Cluj-Napoca, and they have been kept at freezing temperatures $\left(-20^{\circ} \mathrm{C}\right)$. In order to assess in dynamic the oxidative spoilage processes, there have been carried out 3 analyses during the experiment: July 2014, December 2014 and May 2015. The assessment of the oxidative alteration was done by determining the thiobarbituric acid (TBARS), malondialdehyde expressed in mmol/100 g. $10 \mathrm{~g}$ of meat were taken and homogenized in Ultra Turrax apparatus (IKA, Germany), together with a solution prepared from $97.5 \mathrm{ml}$ water and $2.5 \mathrm{ml}$ $4 \mathrm{~N} \mathrm{HCl}$. The entire preparation was allowed to stand at $4{ }^{\circ} \mathrm{C}$ for 3 hours. Filtration was performed and $5 \mathrm{ml}$ of the filtrate were taken over which $5 \mathrm{ml}$ of trichloracetic acid (15\% TCA)/thiobarbituric acid (TBA $0.375 \%$ ) were added. The samples were placed in sealed tubes, and were left in a boiling water bath for 35 minutes, then centrifuged. From the upper layer the absorbance was read at 538 nm $\lambda$ max $=$ UV-VIS with a spectrophotometer (JASCO V-530, USA). For the calculation, the molar absorption coefficient was used for TBARS which is equal to $1.56 \times 10^{5} \mathrm{M}-1 \mathrm{~cm}-1$. In order to assess the degree of contamination of the meat the total load (TPC) and psychrotrophic germs configuration were performed according with the method describe by Dan et al., 2003.The results were statistically analyzed with Origin 8.5 software, using unicategorial ANOVA analyzes. The statistical interpretation of results was based on the value of the probability $(\mathrm{p}<0.05)$.

\section{RESULTS AND DISCUSSIONS}

Comparative evaluation of oxidative spoilage processes

From the results analysis on the oxidative processes it was found that in beef samples the thiobarbituric acid (TBARS) presented in dynamic an upward trend, with values in the first day of the experiment of $6.81 \pm 0.18$ and $11.82 \pm 0.20$ nmol/100 g malondialdehyde (Fig. 1). Since the examined samples were stored at $-20^{\circ} \mathrm{C}$ for the whole duration of the experiment, we consider that the oxidative processes triggered already on the first day, knowing that once initiated, the processes of autoxidation of fatty acids are not stopped even during storage at negative temperatures. Similar results were obtained by Okolie and Osarhiene (2013) in a study on the evaluation of the beef oxidation processes, the TBARS values were $2.44 \pm 0.13 \mathrm{mmol} / \mathrm{g}$ malondialdehyde.

In the case of pork meat, after we analyzed the results obtained regarding the oxidative processes, it was found that the thiobarbituric acid (TBARS) presented in dynamic an upward trend, consistent with the values in the first day of the experiment of $3.40 \pm 0.20$ and $15.19 \pm 0.30$ nmoli/100 g malondialdehyde (Fig. 2). Taking into account the fact that the samples examined were kept at $-20^{\circ} \mathrm{C}$, during the entire period of the experiment, we consider that the oxidative processes were already triggered in the first day, knowing that once started the oxidative processes of fatty acids are not stopped during the storage period at negative temperatures.

Similar results were obtained by Okolie and Osarhiene (2013) in a study regarding the evaluation of oxidative processes in pork meat, in which the TBARS values were $2.91 \pm 0.49 \mathrm{nmol} / \mathrm{g}$ malondialdehyde. 
From analyzing the results obtained regarding the oxidative processes, it was found that in poultry meat the thiobarbituric acid (TBARS) has shown in dynamic an upward trend, uniform, with values in the first day of the experiment in between $14.4 \pm 0.4$ and 19.74 \pm 1.16 nmoli/100 g malondialdehyde (Fig. 3). Similar results were obtained by Okolie and Osarhiene (2013) in a study regarding the oxidative processes in beef, in which the TBARS were $3.95 \pm 0.34 \mathrm{mmol} / \mathrm{g}$ malondialdehyde.

From the analysis of the obtained results regarding the oxidative processes, it was found that in the fish meat the thiobarbituric acid (TBARS) has shown in dynamic an upward trend, uniform, with values in the first day of the experiment of $4.2 \pm 0.2$ and $14.78 \pm 0.19 \mathrm{nmoli} / 100 \mathrm{~g}$ malondialdehyde (Fig. 4). Taking into account that the examined sampled were kept at $-20^{\circ} \mathrm{C}$, during the entire length of the experiment, we consider that the oxidative processes were already triggered within the start of the experiment. Munasingheet al., (2005) have obtained similar results in a study regarding the oxidative processes in fish meat, in which the TBARS values were of $4.55 \pm 0.04$ nmolmalondialdehyde.

The results regarding the evaluation in dynamic of the TPC

The results obtained in this study have shown that the total germ load showed a dynamic descendant trend, uniform, with values in the first of day of the experiment in between $4.9 \pm 0.31$ and $4.1 \pm 0.26 \mathrm{log} \mathrm{cfu} / \mathrm{g}$ (Fig. 5). Taking into consideration that the examined samples were kept at $-20^{\circ} \mathrm{C}$, during the entire length of the experiment, it was found the inactivation of some

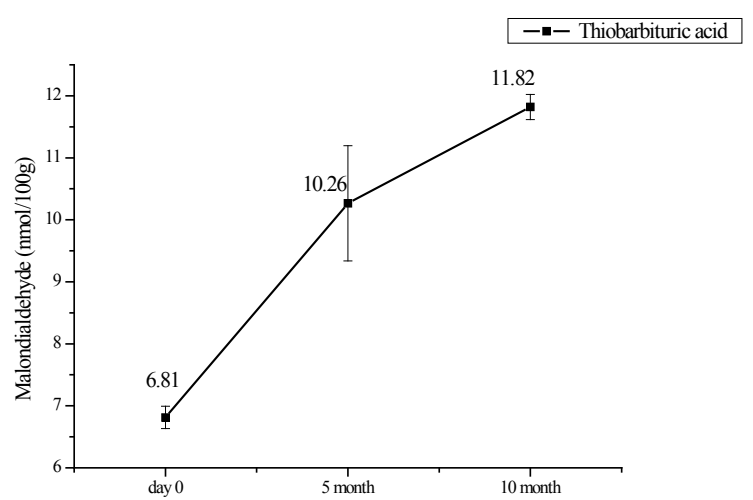

Fig. 1.Thiobarbituric acid values in beef during storage at -20 grade $C(n=3)$ microorganisms, but the majorities were viable. Similar values were obtained by Eiselet al., (1997) in a study regarding the evaluation of oxidative processes in beef, in which the TC was $5.6 \log \mathrm{ufc} / \mathrm{g}$.

In case of pork meat, it was found that the total germ count has shown a descendent downward trend, with values during the first day of the experiment in between $4.55 \pm 0.55$ and $4.01 \pm 0.57$ $\log \mathrm{cfu} / \mathrm{g}$ (Fig. 6). The results differ from those obtained by Daniyan (2011), in a study regarding the evaluation of the oxidative processes in pork meat, in which the TPC was of $47 \times 10^{5}-82.5 \times$ $10^{5} \mathrm{cfu} / \mathrm{g}$.

In the case of poultry meat, it was found that the germ load has shown a descendant evolution in dynamic, with values during the first day of the experiment in between $4.45 \pm 0.44$ and $3.97 \pm 0.45$ $\log \mathrm{cfu} / \mathrm{g}$ (Fig. 7). Similar results were obtained by Vinod et al., (2006) in a study regarding the evaluation of oxidative processes in beef, in which the TC were $2.3 \pm 0.22 \log \mathrm{cfu} / \mathrm{g}$.

In the case of fish meat, it was found that the germ load has shown a descendant evolution in dynamic, with values during the first day of the experiment in between $5.32 \pm 0.51$ and $3.64 \pm 0.44$ log cfu/g (Fig. 8). Similar results were obtained by Deyan et al. (2015) in a study regarding the evaluation of oxidative processes in fish meat, in which the TC was $4.43 \pm 0.52 \log \mathrm{cfu} / \mathrm{g}$.

From the comparative statistical analysis of the results it was found that the highest TBARS values expressed in nmoli/100 g malondialdehyde were high lightened in the case of poultry meat, followed by fish meat, swine and bovine $(\mathrm{p}<0.05)$, results which confirm the data according to which

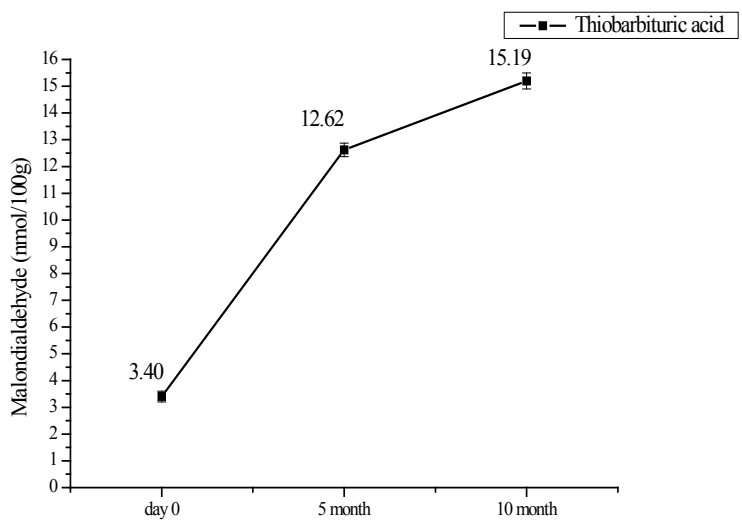

Fig. 2.Thiobarbituric acid values in pork during storage at -20 grade $C(n=3)$ 


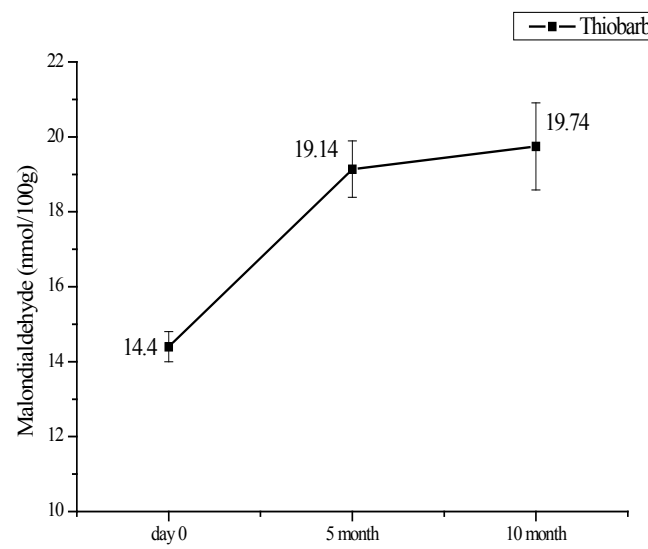

Fig. 3.Thiobarbituric acid values in poultry meat during storage at -20 grade $C(n=3)$

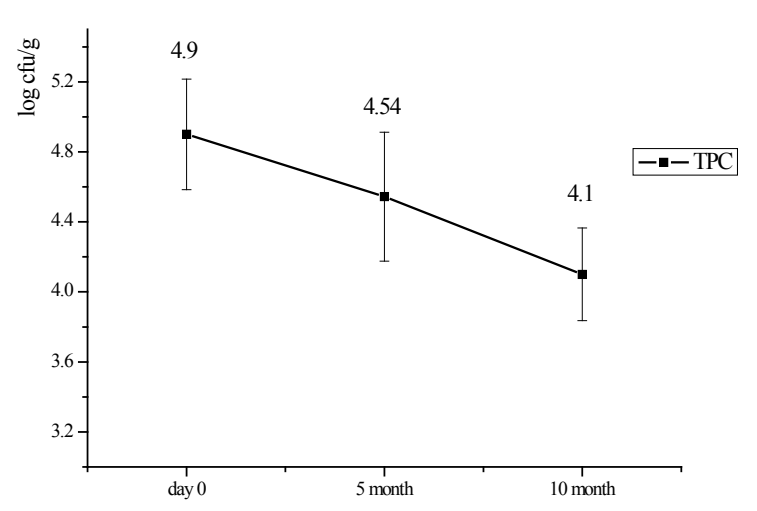

Fig. 5.Total plate count values in beef during storage at $-20^{\circ} \mathrm{C}(\mathrm{n}=3)$

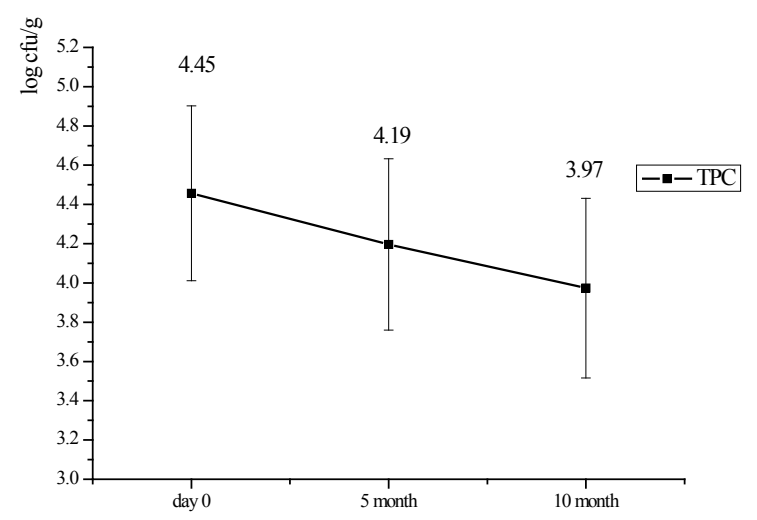

Fig. 7.Total plate count values in poultry meat during storage at $-20^{\circ} \mathrm{C}(\mathrm{n}=3)$

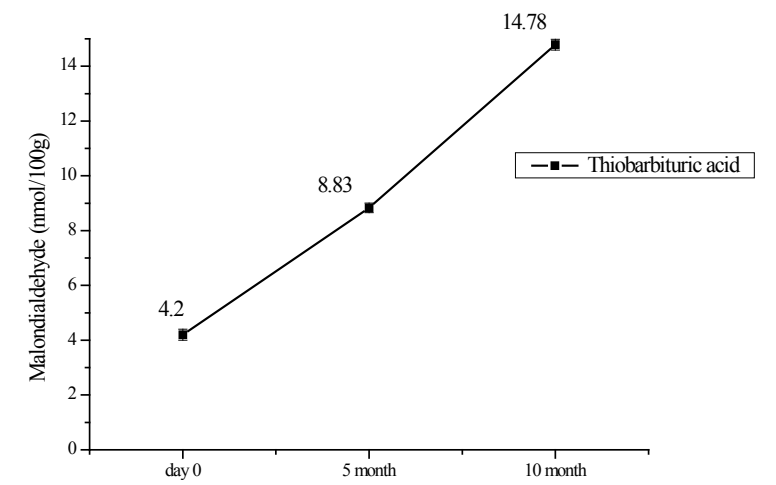

Fig. 4.Thiobarbituric acid values in fish meat during storage at -20 grade $C(n=3)$

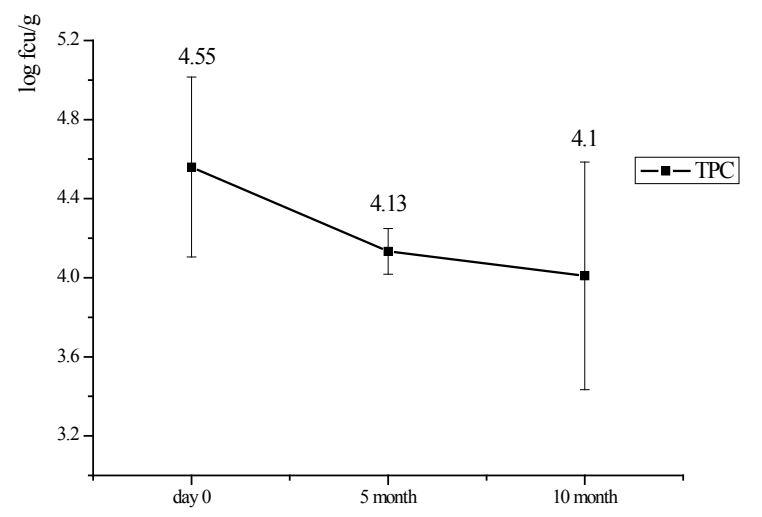

Fig. 6.Total plate count values in pork during storage at $-20^{\circ} \mathrm{C}(\mathrm{n}=3)$

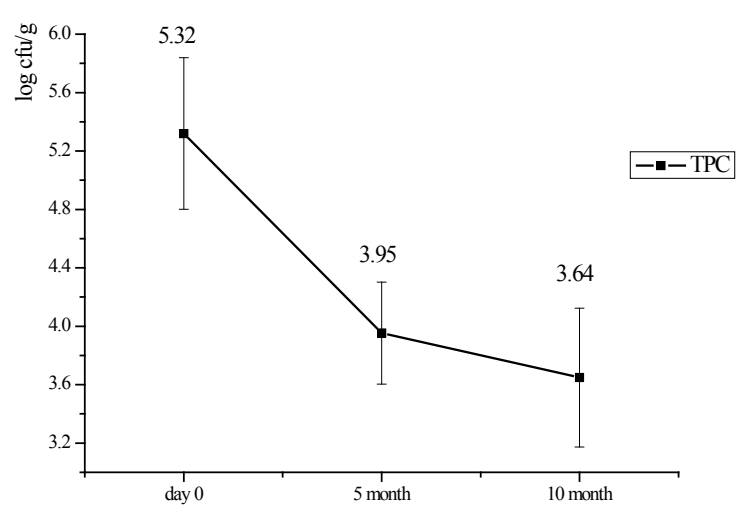

Fig. 8. Total plate count values in fish meat during storage at $-20^{\circ} \mathrm{C}(\mathrm{n}=3)$ 
the samples higher in polyunsaturated fatty acids are more sensitive to the oxidative processes (Addis, 1986; Bele, 2004, Laohabanjong et al., 2009). These values showed that the oxidative processes have started before the samples were introduced in the freezer at $-20^{\circ} \mathrm{C}$. Taking into consideration that the samples were purchased from the market, the oxidative processes were initiated by a series of factors: reducement or even the absence of vitamin E from the meat samples; the germ load relatively high (TPC values 4.5-5.3 $\mathrm{cfu} / \mathrm{g})$; respectively the non-compliant conditions for storage (light, air, because the packages were not hermetically sealed). As consequence, the oxidative alteration during the freezing storage in corresponding conditions (dark, hermetically sealed) did not block or slow the process, on the contrary it speeded it.

\section{CONCLUSION}

The thiobarbituric acid (TBARS) has shown in dynamic an upward trend in all the meat samples examined, the highest values being noticed in poultry meat. The total germ load in the meat samples examined has shown a descendant trend, during the entire period of storage at $-20^{\circ} \mathrm{C}$. There were negative correlations found between the TC values and the TBARS in the analyzed samples. There were no correlations found between the total count and TBARS values in the meat samples, because the highest values of the TC were identified in fish meat, while the highest numbers of the TBARS were revealed in poultry meat.

\section{REFERENCES}

1. Addis PB (1986). Occurrence of lipid peroxidation products in foods. Food Chem Toxicol 24: 1021-1030.

2. .Afford JA, Elliott LE (1960). Lipolytic activity of microorganisms at low and intermediate temperatures, action of Pseudomonas fluorescens on lard. Food Res 25:296-303.

3. Afford JA, Pierce DA(1961). Lipolytic activity of microorganisms at low and intermediate temperatures, activity of microbial lipases at temperatures below $0^{\circ} \mathrm{C}$. J Food Science 26:518- 524.
4. Bele C (2004). Biochimie medicală veterinară. Ed Todesco, Cluj-Napoca.

5. Chan KM, Decker EA (1994). Endogenous skeletal muscle antioxidants. Crit Rev Food Sci Nutr 34:403-426.

6. Daniyan SY (2011). Microbiological Quality of Pork Meat from Local Mammy Market in Niger State, Nigeria, AU JT 14(3):229-231.

7. Dan SD, Rotaru O, Răpuntean Gh, Mihaiu M, Zegrean G (2003). The dynamic of psychrotrophic microflora in beef during slaughtering process. Bul USAMV-CN 60:6771.

8. Deyan S, Ivan V, Hristo D (2015). Microbiological status of fish products on retail markets in the Republic of Bulgaria. International Food Research Journal 22(1):64-6.

9. Eisel WG, Linton R, Muriana M (1997). A survey of microbial levels for incoming raw beef environmental sources and ground beef in a red meat processing plant. Food microbiology 14(3):273-282.

10. Laohabanjong R, Tantikitti C, Benjakul S, Supamattaya K, Boonyaratpalin M (2009). Lipid Oxidation in Fish Meal Stored under Different Conditions on Growth, Feed Efficiency and Hepatopancreatic Cells of Black Tiger Shrimp (Penaeus monodon). Aquaculture 286 (3-4286):283-289.

11. Khan IM, Dill CW, Chandan RC, Shahani KM (1967). Production and Properties of the Extracellular Lipase of Achromobacter lipolyticum. Biochim Biophys Acta 132:68-77.

12. Min B, Ahn DU(2005). Mechanism of lipid peroxidation in meat and meat products-A review. Food Science and Biotechnology 14:152-163.

13. Munasinghe DM, Ohkubo T, Sakai T (2005). The lipid peroxidation induced changes of protein in refrigerated yellowtail minced meat. Fisheries Science 71: 462 - 464.

14. Nashif SA, Nelson FE (1953). The Lipase of Pseudomonas fragi. II. Factors Affecting Lipase Production. J Dairy Science 36:471-480.

15. Okolie NP, Osarhiene T(2013). A comparative study of malondialdehyde contents of some

meat and fish samples processed by different methods. JPSI 2 (4): 26-29.

16. Pikul J, Leszczynski DE, Kummerow FA(1989).Evaluation of three modified tba methods for measuring lipid oxidation in chicken meat. J Agric Food Chem 37: 13091313.

17. Vinod KM, Sachindra N(2006). Changes in quality of chicken curry during frozen storage.

Journal of muscle foods 17(2):141-154. 